Çukurova Üniversitesi Mühendislik Mimarlık Fakültesi Dergisi, 33(1), ss. 219-228, Mart 2018

Çukurova University Journal of the Faculty of Engineering and Architecture, 33(1), pp. 219-228, March 2018

\title{
Bodur Mürver (Sambucus ebulus L.) ile Yün İpliklerin Boyanması
}

\author{
Halil ÖZDEMIR*1 \\ ${ }^{1}$ Osmaniye Korkut Ata Üniversitesi, OMYO, Tekstil, Giyim, Ayakkabı ve Deri Bölümü, \\ Osmaniye
}

Geliş tarihi: 08.02.2018 Kabul tarihi: 14.03.2018

\section{$\ddot{\mathbf{O} z}$}

Son yıllarda tekstil terbiye işletmelerinde kullanılan sentetik boyarmaddelerin ve pigmentlerin kullanımı insan sağlı̆ğ ve çevreye verdiği zararlardan ötürü tartışılmaktadır. Bu sebeple, biyolojik olarak parçalanabilirliği, toksik (zehirli) olmaması, insan sağlığı ve atık su kontaminantı için herhangi bir sorun oluşturmaması nedeniyle doğadaki bitkilerden elde dilen doğal boyarmaddelerin kullanımı artmaya başlamıştır. Bu çalışma kapsamında Sambucus ebulus L. (Bodur mürver) bitkisinin meyve, yaprak ve gövde gibi kısımlarından elde edilen doğal boyarmaddeyle yün iplikleri farklı mordan maddeleri kullanılarak boyanmıştır. Spektrofotometre cihazında yapılan renk ölçümleri ve renk karşılaş̧ırmaları sonucunda, Demir Sülfat $\left(\mathrm{FeSO}_{4}\right)$ ile yapılan mordanlama sonucunda elde edilen $\mathrm{K} / \mathrm{S}$ değerleri ile daha koyu renklere ulaşılabildiği tespit edilmiştir. Sonuç olarak, tıp, eczacılık, gıda ve kimya gibi birçok alanda kullanılan Sambucus ebulus L. bitkisinin özellikle doğal boyamacılık alanında da kullanılabileceği, elde edilen kahverengi ve tonları açısından aspir, ayva, ceviz gibi doğal boyacılıkta kullanılan bitkilere alternatif olabileceği belirtilmiştir.

Anahtar kelimeler: Bodur mürver, Doğal boyama, Renk ölçümü, Mordanlama

\section{Dyeing of Wool Yarn with Dwarf Elder (Sambucus ebulus L.)}

\begin{abstract}
Abstact
In recent years, the use of synthetic dyes and pigments in textile finishing companies has been discussed for their harmful effects on human health and environment. For this reason, the use of natural dyestuffs from plants in the nature has begun to increase because of the biodegradability, toxicity, human health and waste water contamination. In this study, wool yarns were dyed using different mordant materials and natural dyes which is extracted from parts such as berry, leaf and branch of Sambucus ebulus L. (Dwarf Elder). As a result of the color measurements and color comparisons measured in the spectrophotometer, it was determined that the darker colors can be reached by mordanting with Iron Sulphate $\left(\mathrm{FeSO}_{4}\right)$ according to $\mathrm{K} / \mathrm{S}$ values. As a result, it is stated that Sambucus ebulus L. plant, which is used in many fields such as medicine, pharmacy, food and chemistry, can be used in natural dyeing due to its brown and tones and may be an alternative to plants used in natural dyeing such as safflower, quince and walnut.
\end{abstract}

Keywords: Dwarf Elder (Sambucus ebulus L.), Natural dyeing, Color measurement, Mordanting

*Sorumlu yazar (Corresponding author): Halil ÖZDEMIR, halilozdemir@osmaniye.edu.tr 


\section{GíRiş}

Doğal boyalar, gida ve deri sektöründe renklendirme amaçlı kullanımının yanı sıra, tarih öncesi çağlardan beri yün ve ipek gibi doğal protein elyaflarının renklendirilmesinde kullanılmaları ile bilinmektedir [1]. Doğal boyarmaddeler, doğada bazı bitkiler, böcekler ve mantarlar tarafindan sentezlenen renkli maddelerdir. Başlıca doğal tekstil boyarmaddeleri ise bitkilerden elde edilir [2].

Bitkilerin yapısında bulunan boyarmaddeler bir taraftan boya miktarına ve cinsine, diğer taraftan bitki kısmına göre değişik yöntemler ile elde edilmektedir. Günümüzde kullanılan başlıca yöntemler boyarmadde ekstraksiyonu, katı-sıv1 ekstraksiyonu ve distilasyon yöntemleridir. Boyarmadde, boyayı taşıyan bitki kısımlarından, genellikle distilasyon yöntemiyle elde edilmektedir [3]. Bitkiler, genellikle suyla ekstrakte edildiklerinde daha az renkli bileşik vermektedirler. Doğal boyaların elde edilme maliyetleri sentetik boyaların elde edilme maliyetleri ile kıyaslandığında daha pahalı olduğu saptanmış ve bu durum sentetik boyaların daha yaygın kullanılmasına neden olmuştur. Ancak doğal boyalar, sentetik boyalara göre toksik (zehirli) ve kanserojen olmamaları ve biyolojik olarak parçalanabilirliğe sahip olmaları gibi önemli avantajlara sahiptirler. Buna ilaveten; doğal boyalar, çevre kirliliğine neden olmamakta ve atık su problemi (kontaminantı) teşkil etmemektedirler [4-6].

Latince adı, Sambucus ebulus L. (Dwarf elder) olan mürver bitkisi ülkemizde, cüce mürver, bodur mürver, azıotu ve yabani mürver olarak adlandırılmaktadır. Dipsacales takımı, Caprifoliaceae (hanımeligiller) familyasından, çok yıllık, otsu ve çiçekli tipindeki mürverin ana vatanı Avrupa ve Batı Asya olup hemen hemen bütün Anadolu yetiştiği bilinmektedir. Yaprak (Folia Sumbuci ebuli), çiçek ve meyveleri tıp, gıda, eczacılık ve kimya alanında kullanılmaktadır. Sambucus ebulus L., yapraklarında uçucu yă̆, şeker ve bazı organik asitler barındırmaktadır. Yapraklar ve meyveler müshil şeklinde geleneksel olarak kullanılmakta, çiçekler ise terletici ve hafif yatıştırıcı bir etki göstermektedir.

Meyvelerinde ise acılık hissi veren bir madde, tanen, şeker ve valerian asidinden başka bol miktarda renk maddesi bulundurmaktadır [7]. Bitkinin meyvesinde bulunan doğal boya olarak kullanılabilen kromofor grubun Şekil 1'de görüldüğü gibi antosiyaninlerin türevi olan sambusiyanin olduğu bilinmektedir.

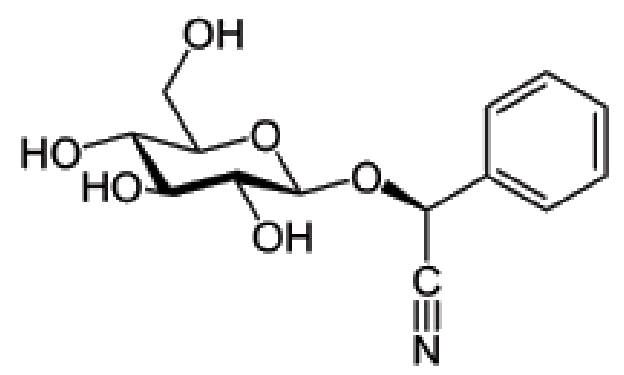

Şekil 1. Kimyasal olarak Sambusiyanin yapısı [4]

Sambucus ebulus L. (Dwarf elder) bitkisi kullanılarak özellikle tıp, eczacılık ve gida alanlarında birçok bilimsel çalışmanın yapılmasına rağmen bitkinin meyvesi dışında kısımlarının da doğal boyarmadde olarak kullanılabilirliği üzerine detaylı çalışmalara rastlanmamıştır. Bunu üzerine çalışma kapsamında Sambucus ebulus L. bitkisinin meyvesi, yaprağı ve dallarından ekstrakte edilen doğal boyarmaddeler ile yün iplikler farklı mordan maddeleri ve konvansiyonel boyama metodu kullanılarak boyanmış, elde edilen renkler spektrofotometrik olarak değerlendirilmiştir.

\section{2. ÖNCEKİ ÇALIŞMALAR}

Literatürde Sambucus ebulus L. bitkisinin meyvesi, yaprakları ve kökü kullanılarak özellikle tıp, geleneksel tıp, eczacılık ve kimya alanlarında pek çok araştırmanın olduğu görülmektedir. Bunlardan Jabbari ve arkadaşları derlemelerinde eskiden beri dünyanın pek çok bölgesinde tedavi amaçlı kullanılan bitkinin tedavi edici flavonoid ve lektin maddesi içerdiği, soğuk algınlı̆̆ı, ağrı, yaralanma ve enfeksiyon tedavileri yanında kanser ve metobolik rahatsızlıklar için de kullanılabileceğini belirtmişlerdir [8]. 
Jiménez ve arkadaşları [9] derleme çalışmasında, tıbbi bir bitki olan Sambucus ebulus L. (bodur mürverin) gida olarak kullanımının toksisitesi nedeniyle sınırlı olduğunu, son yıllarda hem kimya ve farmakoloji alanında araştırıldığını, bitkide bulunan proteinin (lektin), zehirli ebulin maddesinden izole edilip kullanılabileceğini vurgulamışlardır. Jiménez ve arkadaşları [10] diğer bir çalışmalarında bitkinin meyvesinin sağlık sektörü için önemli olan polifenol ve antiyosiyanin gibi kimyasallar barındırdığını ve antioksidan aktivite gösterdiğini belirterek, değerli bir besin kaynağı alabileceğine işaret etmişlerdir.

Ebrahimzadeh ve arkadaşları [11] ise çalışmalarında gece yanığına sebep olan "Paederus Dermatitis" böceğinden etkilenen hastalarda Sambucus ebulus L. meyvesinin ekstraktının klinik etkisi araştırılmış ve tedavinin medikal uygulama açısından etkili olduğu bildirilmiştir.

Yeşilada ve arkadaşları [12] çalışmalarında Anadolu'da geleneksel tıp içerisinde öne çıkan Sambucus ebulus L. yapraklarının harici olarak römatizmal ağriları dindirmede, apse uygulamalarında, dahili olarak ise hemeroid ve karın ağrısı için kullanabildiği, ayrıca yapraklardan $\mathrm{MeOH}$ kullanılarak izole edilen "flavonol glycosides" maddesinin ülser hastalığında kullanılabileceğini belirtmişlerdir.

Schwaiger ve arkadaşları [13] ise bitkinin yapraklarından ekstrakte edilen "ursolic asidin" kronik iltihaplı hastalıkların tedavisinde kullanılabileceğini ortaya koymuşlardır. Benzer bir çalışmada Süntar ve arkadaşları [14] bitkinin yapraklarından metanol kullanılarak yapılan ekstraksiyon sayesinde ortaya çıkarılan bir flavonoid türevinin (quercetin 3-O-glucoside) ve hesaplanmış bir aktif kompanentin, yara tedavisi için kullanılabileceğini bildirmişlerdir.

Ebrahimzadeh ve arkadaşları [15] yapmış oldukları çalışmada, bitkinin çiçeklerinden metanol kullanılarak yapılan ekstraksiyon sonucunda, antioksidan bir etkinin olduğunu tespit etmişlerdir. Benzer şekilde Ebrahimzadeh ve arkadaşları [16] başka bir çalışmasında bitkinin meyvesi, yaprakları ve kökünün metanol kullanılarak yapılan ekstraksiyon sonucunda antiinflamatuvar (iltihap giderici) bir etki tespit etmişlerdir.

Balkan ve arkadaşları [17] bitkinin yapraklarından izole edilen "Sambulin A" ve "Sambulin B" maddesinin geleneksel tedavi yaklaşımlarını destekleyici bir biçimde romatizmal hastalıklarda kullanılabileceğini bildirmişlerdir.

Ülkemizin birçok bölgesinde ormanlık alanlarda ve yol kenarlarında yetiştiği görülen mürver bitkisinin iki türünden biri olan Sambucus ebulus L. (Dwarf elderberry) ile tekstil ve doğal boyama alanlarında yapılan bilimsel çalışmalar incelendiğinde ise, Dayığlu ve arkadaşları [6] konvansiyonel ve mikrodalga boyama yöntemlerini kullanarak Sambucus ebulus L. meyvesinden ekstrakte ettikleri doğal boya ile ipekli kumaşları boyamışlar, boyama öncesi kullanılan plazma uygulaması ve boyama sonrası kullanilan katyonik polimer ve fikse kimyasallarının boyama üzerindeki etkilerini tespit etmişlerdir. Canpolat ve arkadaşları [4] çalışmalarında ise farklı kimyasallar kullanılarak ön mordanlamaya tabi tutulan ipekli kumaşların Sambucus ebulus L. meyvesinden elde edilen boya ekstraktı ile konvansiyonel ve ultrasonik yönteme göre boyama işlemleri gerçekleştirilmiş ve boyama sonuçları spektrofotometrik ve haslık açısından karşılaştırılmıştır.

Bitkinin meyvesinde bulunan doğal boya olarak kullanılabilen kromofor grubun Şekil 1'de görüldüğü gibi antosiyaninlerin türevi olan sambusiyanin olduğu bilinmektedir.

\section{MATERYAL VE METOT}

\subsection{Materyal}

Çalışmada Doğu Akdeniz Bölgesi menşeli koyunların yünlerinden eğrilmiş \%100 saf straygarn yün iplikleri ( $\mathrm{Nm} \mathrm{4/2,} 256 \mathrm{t} / \mathrm{m}$ ) Osmaniye'de bulunan Karatepe Kilim Kooperatifinden tedarik edilmiş, boyamalarda kullanılmak üzere çile sarım makinesinde $3 \mathrm{~g}$ ağırlığında çile numuneleri hazırlanmıştır. 
Adana İli Akçatekir/Pozantı bölgesinden ağustos ayında Sambucus ebulus L. (bodur mürver) bitkisinden (Şekil 2) meyve, yaprak ve gövde örnekleri toplanmış ve güneş görmeyen havadar bir alanda kurumaya bırakılmış, kuruma işlemi sonunda doğrayıcı ve öğütücü kullanılarak küçük parçalar haline getirilmiştir (Şekil 3).

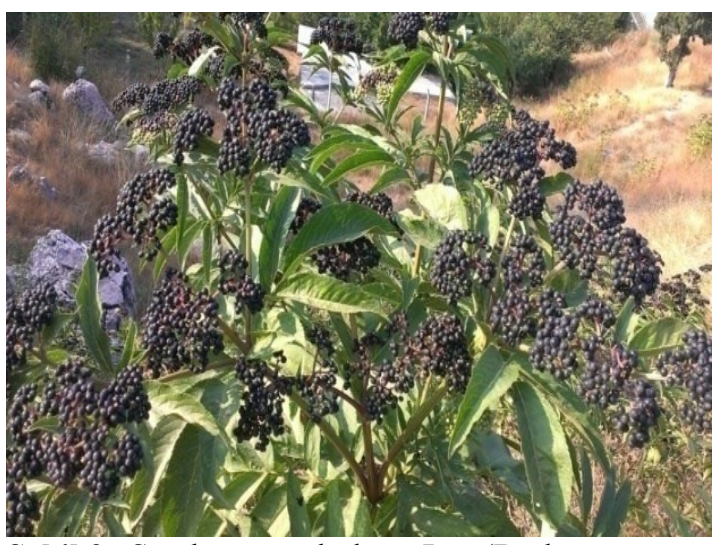

Şekil 2. Sambucus ebulus L. (Bodur mürver, Akçatekir/Pozantı bölgesi)

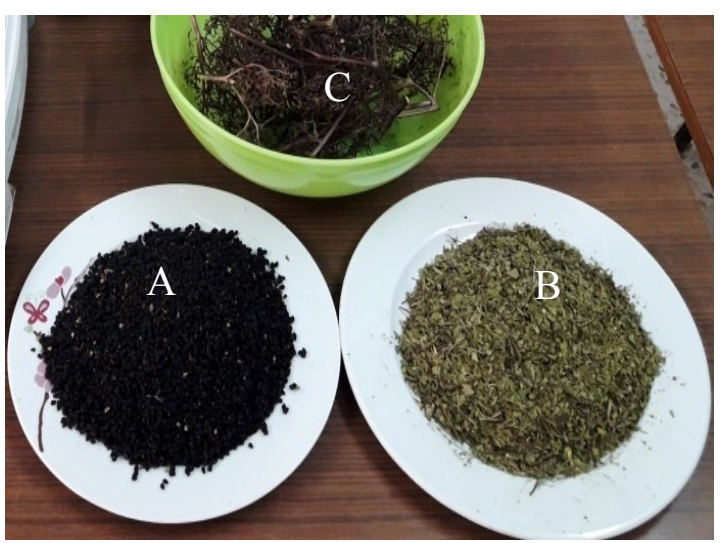

Şekil 3. Kurutulmuş bitki kısımları (A: meyve, B: yaprak ve C: gövde)

\subsection{Metot}

Boya banyosu $1 \mathrm{~L}$ damıtık su içerisinde $20 \mathrm{~g}$ bitki numunesi bir saat kaynatılıp filtre edilmesi ile $\% 2$ konsantrasyonda hazırlanmıştır. Çalışmada ön mordanlama işlemi uygulanmış, mordanlamanın renk üzerindeki etkisini ortaya çıkarabilmek amacıyla, Şap diye tabir edilen Potasyum
Alüminyum Sülfat $\left(\mathrm{KAl}\left(\mathrm{SO}_{4}\right)_{2}\right)$ ve Demir Sülfat $\left(\mathrm{FeSO}_{4}\right)$ mordanları kullanılmıştır. Islatılmış yün iplikleri \%3 konsantrasyonda, 1:50 flotte oranında $80{ }^{\circ} \mathrm{C}$ 'de 45 dakika süreyle ön mordanlama işlemine tabi tutulmuş, akabinde herhangi bir yıkama ve durulama işlemi yapılmadan sıkılarak boyamaya hazır hale getirilmiştir. 1:50 flotte oranı kullanılarak, 0,15 L orijinal boya ekstraktıyla çile halindeki ipliklerin çektirme yöntemine göre boyamaları gerçekleştirilmiştir. Boya banyolarının $\mathrm{pH}$ değeri 5 olduğundan $\mathrm{pH}$ için herhangi bir kimyasal kullanılmaya gerek duyulmamıştır. Boyamaya $40{ }^{\circ} \mathrm{C}$ 'de başlanmış, $80{ }^{\circ} \mathrm{C}$ 'ye kadar yükseltilmiştir. Daha sonra numuneler bu sicaklıkta 60 dakika muamele görmüştür. Boyama esnasında boya banyosunun karıştırılmasına özen gösterilmiştir. Ardından boyanmış numunelerin non-iyonik bir deterjan (Setalan HE, Setaş Kimyasal) kullanılarak 2 g/L konsantrasyonda, $80{ }^{\circ} \mathrm{C}$ 'de 30 dakika süreyle sıcak yıkamaları tamamlanmış, durulama işleminin ardından gölge bir odada kurutulmuştur. Spektrofotometre cihazında renk ölçümleri yapabilmek için, boyanmış iplikler, numune iplik sarım makinesinde karton kartlar üzerine, yüzeyi kapatacak şekilde hassas bir biçimde sarılmıştır.

Boyanmış ipliklerin renk koordinatlarının belirlenmesi için Minolta CM 3600 D model spektrofotometre ile 400-700 nm dalga boyu arasında, $\quad$ D65/10 $10^{\circ}$ 1şık kaynağında ölçümler gerçekleştirilmiştir. Boyama kuvveti olarak değerlendirilen K/S (Color Strength) değerleri Kubelka Munk (1) eşitliğine göre hesaplanmıştır. Ölçümlerde hatayı minimize etmek ve en doğru renk değerlerini tespit etmek amaciyla numunelerinin 5 farklı bölgesinden ölçümler alınarak ve ortalamalar değerlendirilmiştir.

$\mathrm{K} / \mathrm{S}=\left(1-\mathrm{R}^{2}\right) / 2 \mathrm{R}$

Eşitlikte K; 1şı k absorpsiyonu ile ilgili bir sabit olup, çoğunlukla boyarmaddeye bağlıdır. S; 1şık saçılımı (yansıması) ile ilgili bir sabit olup, sadece tekstil materyaline bağlıdır. $\mathrm{R}$ ise maksimum 1 şık absorpsiyonunun dalga boyunda (400 nm) ölçülen boyalı numunenin yansıma değeridir. 


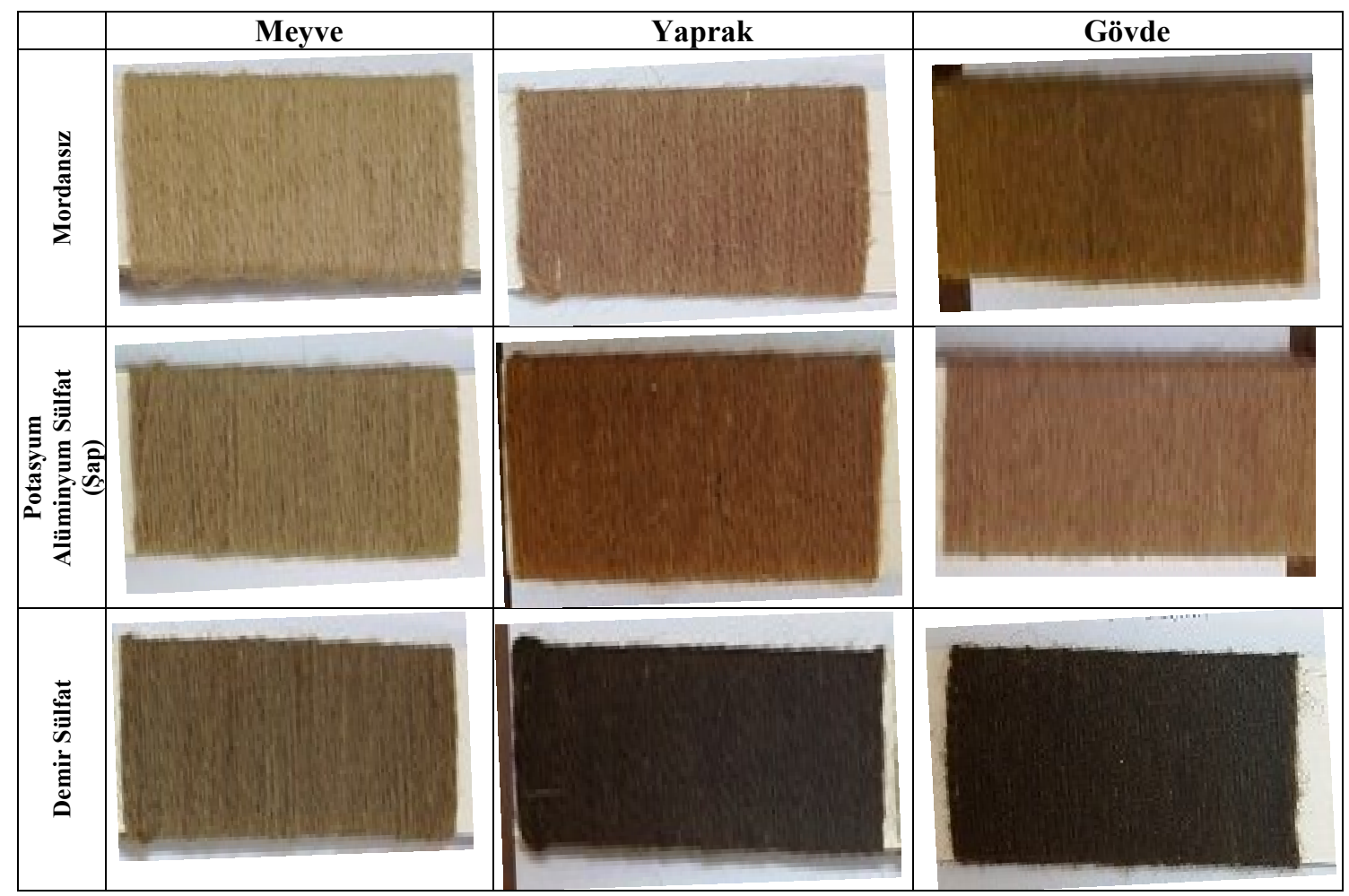

Şekil 4. Boyanmış iplik görüntüleri

Renk farkının tespit edilmesinde ise CIELab formülasyonu (2) kullanılmış (DIN 6174), L*; açıklık-koyuluk, a*; kırmızılık-yeşillik, b*,sarılıkmavilik değerleridir. Örneklerin $\Delta \mathrm{E}^{*}$ değeri, renk farklılığının ifadesidir. $\Delta \mathrm{E}^{*}<1$ ise, karşılaştırılan iki renk arasında farkın az olduğunu; $\Delta \mathrm{E}^{*}>1$ ise daha fazla olduğunu ifade etmektedir. $\Delta \mathrm{L}^{*}$ değerinin (-) olması, örneğin standarda göre daha koyu olduğunu, $(+)$ olması ise daha açık olduğunu göstermektedir. $\Delta C^{*}$ değerinin $(+)$ olması ise yüksek kromayı yani doygunluğu ifade eder. $\mathrm{a}^{*}$ değeri arttıkça renk kırmızıya, azaldıkça yeşile, b* değeri arttıkça renk sarıya, azaldıkça maviye dönmektedir.

$\Delta \mathrm{E}^{*}=\left[\left(\Delta \mathrm{a}^{*}\right)^{2}+\left(\Delta \mathrm{b}^{*}\right)^{2}+\left(\Delta \mathrm{L}^{*}\right)^{2}\right]^{1 / 2}$

\section{RENK ÖLÇÜM SONUÇLARI VE DEĞERLENDİRME}

İki farklı mordan kullanarak kahverengi ve tonlarında elde edilen renklerin Spektrofotometrik renk ölçüm sonuçları Çizelge 1'de belirtilmektedir. Çizelge 1'de, mürver bitkisinin meyve ekstraktının mordansız olarak boyanması ile yün iplikleri için bej rengi elde edilirken, şap ve demir sülfat mordanlarının kullanımında ise taba rengine doğru bir koyulaşmanın olduğu görülmektedir. Benzer şekilde yaprak ekstraktı ile yapılan boyamalarda da demir sülfat mordan kullanımı ile rengin somon renginden koyu kahverengine doğru değiştiği göze çarpmaktadır. Bodur mürver bitkisinin gövdesinde elde edilen ekstrakt ile yapilan boyamalarda ise Açık kahverenginden koyu kahverengine doğru bir koyulaşma olduğu tespit edilmiştir (Şekil 4). Resimlerle ortaya konan bu farklılığı, Çizelge 1'de gösterilen renk ölçüm sonuçları da desteklemektedir. Çizelgedeki değerlerden her bir ekstrakt için $\mathrm{L}^{*}$ değerlerindeki düşüş ile rengin açıklık değerinin azaldığı (koyulaştığı) anlaşılmakta, a* değerlerine nazaran $\mathrm{b}^{*}$ değerlerinin yüksek olması ile sarılık/mavilik değerinin kırmızılık/yeşillik değerine nazaran daha baskın olduğu görülmektedir (Şekil 5-6). Benzer 
şekilde $\mathrm{H}$ renk tonu değerleri ve $\mathrm{K} / \mathrm{S}$ olarak tabir edilen renk kuvveti (Color Strength) değerlerinin artması da rengin koyulaşması ile ilişkilendirilebilmektedir (Şekil 7-8).

Çizelge 1. Boyanmış yün ipliklerinin renk ölçüm sonuçları

\begin{tabular}{|l|r|r|r|r|r|r|c|}
\hline \multirow{2}{*}{$\begin{array}{l}\text { Doğal Boyamada Kullanılan } \\
\text { Ekstaktlar }\end{array}$} & \multicolumn{1}{|c|}{ Renk Ölçüm Sonuçları } \\
\cline { 2 - 8 } & \multicolumn{1}{|c|}{$\mathbf{a}^{*}$} & \multicolumn{1}{|c|}{$\mathbf{b}^{*}$} & \multicolumn{1}{|c|}{$\mathbf{C}^{*}$} & \multicolumn{1}{|c|}{ K } & \multicolumn{1}{|c|}{ K/S } & Renk \\
\hline Meyve (mordansız) & 57,1 & 9,34 & 17,46 & 19,8 & 61,86 & 4,9 & Bej \\
\hline Meyve (şap) & 43,91 & 5,74 & 17,55 & 18,46 & 71,88 & 9,73 & Koyu Bej \\
\hline Meyve (demir sülfat) & 38,31 & 4,92 & 17,87 & 18,54 & 74,6 & 14,59 & Taba \\
\hline Yaprak (mordansız) & 42,35 & 13,07 & 14,52 & 19,54 & 48,02 & 17,53 & Somon \\
\hline Yaprak (şap) & 37,33 & 11,89 & 20,22 & 23,46 & 59,56 & 21,43 & Hardal \\
\hline Yaprak (demir sülfat) & 24,96 & 5,27 & 11,46 & 12,61 & 65,28 & 26,94 & K. Kahve \\
\hline Gövde (mordansız) & 43,92 & 11,71 & 14,19 & 18,39 & 50,47 & 13,34 & A. Kahve \\
\hline Gövde (şap) & 40,3 & 7,31 & 26,13 & 27,13 & 74,38 & 22,05 & A. Somon \\
\hline Gövde (demir sülfat) & 23,59 & 4,35 & 9,88 & 10,8 & 66,24 & 23,64 & K. Kahve \\
\hline
\end{tabular}

Çizelge 2. Renk farkı sonuçları

\begin{tabular}{|c|c|c|c|c|c|l|}
\hline Standart & Numune & $\Delta \mathbf{L}^{*}$ & $\Delta \mathbf{a}^{*}$ & $\Delta \mathbf{b}^{*}$ & $\Delta \mathbf{E}$ & Renk Karşılaştırma \\
\hline Meyve (mordansız) & Meyve (şap) & $-13,19$ & $-3,6$ & 0,09 & 13,67 & $\begin{array}{l}\text { Daha koyu, daha } \\
\text { yeşil, daha sarı }\end{array}$ \\
\hline Meyve (mordansız) & Meyve (demir sülfat) & $-18,79$ & $-4,42$ & 0,41 & 19,31 & $\begin{array}{l}\text { Daha koyu, daha } \\
\text { yeşil, daha sarı }\end{array}$ \\
\hline Yaprak (mordansız) & Yaprak (şap) & $-5,02$ & $-1,18$ & 5,7 & 7,69 & $\begin{array}{l}\text { Daha koyu, daha } \\
\text { yeşil, daha sarı }\end{array}$ \\
\hline Yaprak (mordansız) & Yaprak (demir sülfat) & $-17,39$ & $-7,8$ & $-3,06$ & 19,30 & $\begin{array}{l}\text { Daha koyu, daha } \\
\text { yeşil, daha mavi }\end{array}$ \\
\hline Gövde (mordansız) & Gövde (şap) & $-3,62$ & $-4,4$ & 11,94 & 13,23 & $\begin{array}{l}\text { Daha koyu, daha } \\
\text { yeşil, daha sarı }\end{array}$ \\
\hline Gövde (mordansız) & Gövde (demir sülfat) & $-20,33$ & $-7,36$ & $-4,31$ & 22,05 & $\begin{array}{l}\text { Daha koyu, daha } \\
\text { yeşil, daha mavi }\end{array}$ \\
\hline
\end{tabular}

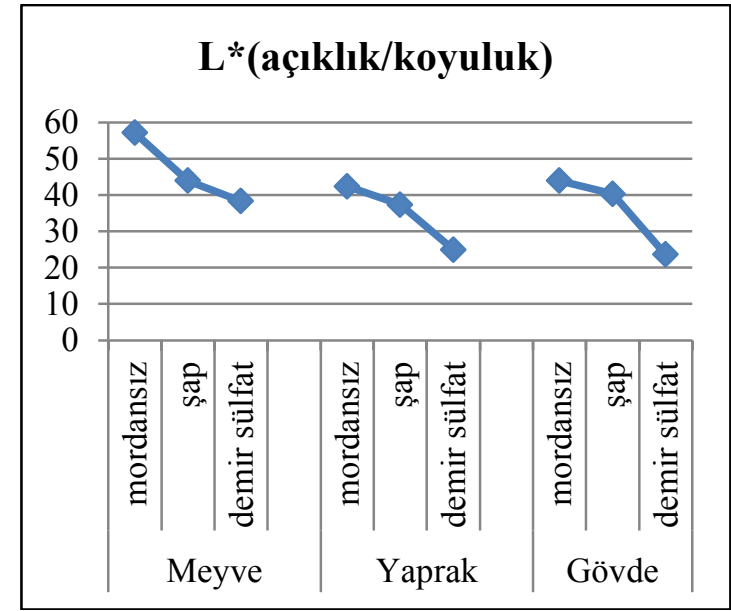

Şekil 5. Boyanmış numunelerin L*(açıklık/koyuluk) değerleri

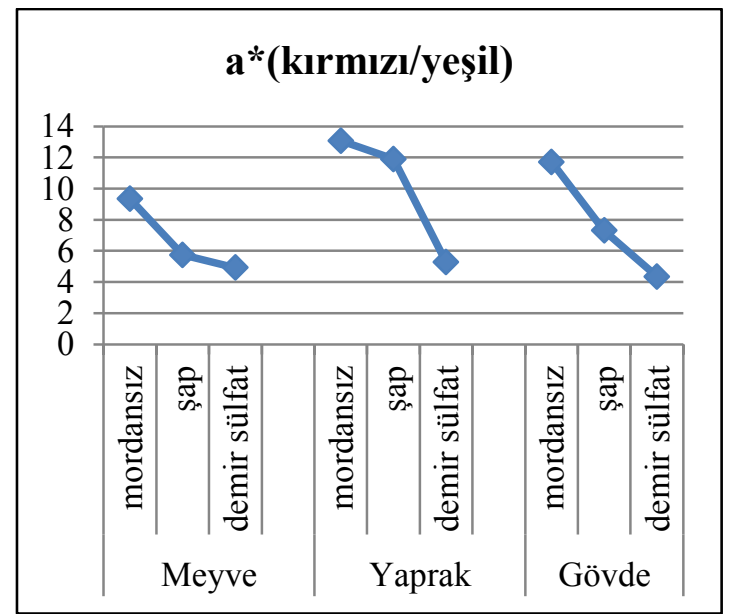

Şekil 6. Boyanmış numunelerin a*(kırmızılık/yeşillik) değerleri 


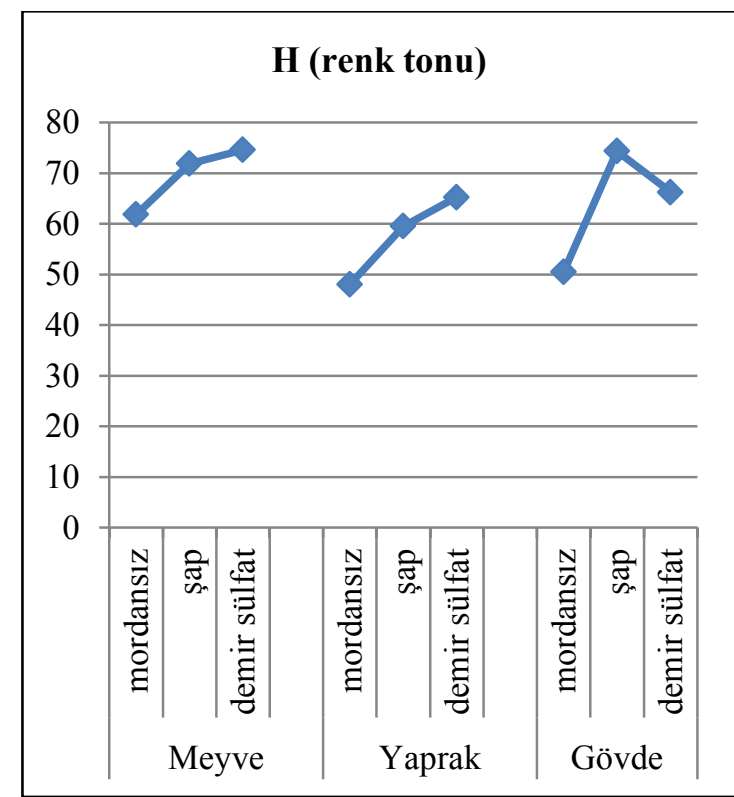

Şekil 7. Boyanmış numunelerin H (renk tonu) değerleri

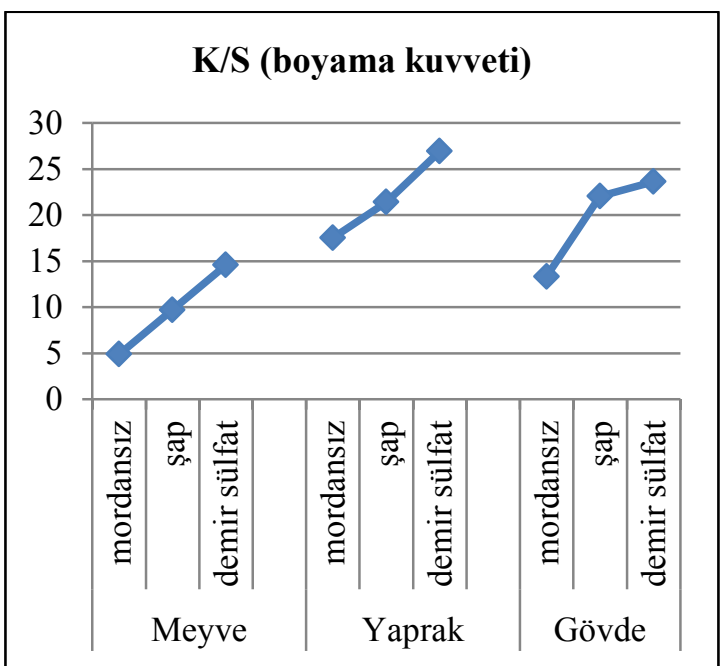

Şekil 8. Boyanmış numunelerin $\mathrm{K} / \mathrm{S}$ (boyama kuvveti) değerleri

Doğal boyamada mordan olarak kullanılan metal iyonları, kararlı kompleks yapılar oluşturarak boya grubunun elyafa bağlanmasına yardımcı olmakta, kullanılan metal iyonuna göre farklı parlaklık özellikleri gösterebilmektedir. Kimyasal formülasyon içerisinde Alüminyum (III) ve Demir (II) iyonları yün elyafı ve doğal boyarmadde ile farklı bölgelerde kompleksler oluşturabilmektedir. Böylelikle rengin tonunda farkliliklar olabilmektedir [18].

Çizelge 1'deki L* ve K/S değerlerine bakıldığında da, çalışma kapsamında yapılan boyamalar içerisinde en koyu renklere mürverin yaprak ve gövde kısımlarından ekstakte edilen doğal boyarmaddeler ve demir sülfat mordanı kullanımı ile ulaşıldığı tespit edilmiştir. Bu durum, demir sülfatın hem yün elyafı ile hem de mürverin "Sambusiyanin" boyarmaddesi ile kararlı kompleks yapılar oluşturmasıyla izah edilebilir. Bir başka ifadeyle yüksek K/S değerlerinin nedeni, hem boyarmadde moleküllerinin hidroksil grupları hem de yün elyafinda bulunan amino ve karboksilik asit gibi fonksiyonel grupların arasında metal mordanların koordinasyon kompleksleri oluşturma yeteneğidir. Demirin bu güçlü koordinasyon eğilimi, alüminyuma nazaran lif ve boya arasındaki etkileşimi arttırarak yüksek boya alımı sağlamaktadır [19].

Tekstilde doğal boyama işlemlerinde genellikle yıkama, sürtünme ve 1şık gibi haslık değerlerinin yükselmesi için kullanılan mordan kimyasallarının boyama üzerindeki etkisini tespit edebilmek amacıyla, çalışma kapsamında toplam renk farkı $(\Delta \mathrm{E})$ değerleri de hesaplanmıştır. Renk kıyaslamalarında mordan kullanılmadan yapılan renk ölçümleri standart (referans) alınarak, meyve, yaprak ve gövde ekstraktlarının kendi aralarındaki renk farkları, Eşitlik (2) formülüne göre hesaplanarak Çizelge 2'de gösterilmiştir. Çizelge 2'deki sonuçlar incelendiğinde toplam renk farkının $(\Delta \mathrm{E})$ beklenildiği gibi kabul değerlerinin $(>1)$ üzerinde olduğu görülmekte, bu durumun boyama öncesi yapılan ön mordanlama işleminden kaynaklı olduğu söylenebilmekte, ayrica mordan kullanılarak yapılan boyamalar sonucunda genel itibariyle daha koyu ve daha yeşil renklerin oluşuğu söylenebilmektedir.

\section{SONUÇ}

Çalışma kapsamında, literatürde tıp, eczacılık, kimya gibi birçok bilimsel alanda çalışmalara kaynaklık eden Sambucus ebulus L. (bodur 
mürver) bitkisi içerisinde kimyasal olarak varlığ tespit edilen Sambusiyanin boyarmaddesinin doğal boyarmadde olarak kullanılabilirliği araştırılmıştır. $\mathrm{Bu}$ kapsamda Adana İli Akçatekir yaylasından mürver bitkisinin boyarmadde olarak kullanılması düşünülen meyve, yaprak ve gövdeleri toplanmış, kurutulmuş ve ekstrakte edilmiştir. Yün ipliklerin boyanması, farklı mordan maddeleri ile ön mordanlama işlemi yapılarak çektirme yöntemine göre tamamlanmıştır. Boyanmış numunelerin renk analizinde spektrofotometre cihazı kullanılarak, sonuçlar sayısal olarak tespit edilmiş ve değerlendirilmiştir. Doğal boyamalar sonucunda, bitkinin araştırılan meyve, yaprak ve gövde kısımlarından genel itibariyle kahverengi ve tonlarında renkler elde edilmiş, mordan kullanılarak, bitkinin yaprak ve gövdesiyle yapılan boyamalar neticesinde meyveye nazaran daha yüksek $\mathrm{K} / \mathrm{S}$ değerlerine ve daha koyu tonlara ulaşıldığ elde edilmiş doğal boyarmadde, tekstil terbiyesinde ve özellikle doğal boyamacılık alanında, geleneksel el halısı, kilim vb. dokumalarında tercih edilen yün ipliklerin renklendirilmesinde kullanılabilmektedir.

\section{KAYNAKLAR}

1. Osman, E., El-Zaher, N.A., 2011. Effect of Mordant Type on Thermal Stability and Fastness Properties of Silk Fabric Dyed with Natural Dye "Sambucus Nigra", Research Journal of Textile and Apparel, 15(2), 61-70.

2. Tekstil Endüstrisinde Doğal Boyama, http://www.yesilaski.com/tekstil-endustrisindedogal-boyama.html, Erişim tarihi: 21.11.2017.

3. Galip, F., 2007. Bögürtlen (rubus sp.) Meyvesinin Karbon Dioksit ile Süper Kritik Ekstraksiyonundan Doğal Boyarmadde Eldesi ve Uygulanabilirliği, Yüksek Lisans Tezi, Gazi Üniversitesi Fen Bilimleri Enstitüsü.

4. Canbolat, Ş., Acar, K., Merdan, N., 2013. Sambucus ebulus L. (Şahmelik) Bitkisinden Ekstrakte Edilmiş Doğal Boyarmadde ile İpekli Materyallerin Boyanmas1, İstanbul Ticaret Üniversitesi Fen Bilimleri Dergisi, Y11: 12 (23), 103-114.
5. Park, S.J., Park, Y.M., 2010. Eco-dyeing and Antimicrobial Properties of Chlorophyllin Copper Complex Extracted from Sasa Veitchii, Fibers and Polymers, 11(3), 357-362.

6. Dayığlu, H., Kut, D., Merdan, N., Canpolat, Ş., 2015. Effect of Dyeing Properties of Fixing Agent and Plasma Treatment on Silk Fabric Dyed with Natural Dye Extract Obtained from Sambucus ebulus L. Plant, Procedia - Social and Behavioral Sciences, World Conference on Technology, Innovation and Entrepreneurship, $195,1609-1617$.

7. http://www.agaclar.org/agac.asp?id=390, Erişim tarihi: 21.11.2017.

8. Jabbari, M., Daneshfard, B., Emtiazy, M., Khivey, A. Hashempur M.H., 2017. Biological effects and Clinical Applications of Dwarf Elder (Sambucus ebulus L): A Review, journal of Evidence Based Complementary Alternative Medicine, 22(4), 996-1001.

9. Jimenez, P., Tejero J., Cordoba-Diaz, D., Quinto, E.J., Garrosa, M., Gayoso, M.J., Girbes, T., 2015. Ebulin from Dwarf Elder (Sambucus ebulus L): a Mini Review, Toxins (Basel), 25(3), 648-658.

10. Jimenez, P., Cabrero, P.,Basterrechea, J.E., Tejero J., Cordoba-Diaz, D., ., Cordoba-Diaz, M., Girbes, T., 2014. Effects of Short-Term Heating on Total Polyphenols, Anthocyanins, Antioxidant Activity and Lectins of Different Parts of Dwarf Elder (Sambucus ebulus L), Plant foods Human Nutrition, 69(2), 168-174.

11. Ebrahimzadeh, M.A., Rafati, M.R., Damchi, M., Golpur, M. Fathiazed, F., 2014. Treatment of Paederus Dermatitis with Sambucus Ebulus Lotion, Iranian Journal of Pharmaceutical Research, 13(3), 1065-1071.

12. Yeşilada, E., Gürbüz, I., Toker, G., 2014. AntiUlcerogenic Activity and Isolation of the Active Principles From Sambucus ebulus L. Leaves, Journal of Ethnopharmacology, 153(2), 478-483.

13. Schwaiger, S., Zeller, I., Pölzelbaurer, P., Frotschnig, S., Laufer, G., Messner, B., Pieri V., Stuppner, H., Bernhard, D., 2011. Identification and Pharmacologyical Characterization of The Anti-Inflammatory Principal of The Leaves of Dwarf Elder 
(Sambucus ebulus L.), Journal of Ethnopharmacology, 133(2), 704-709.

14. Süntar, P., Akkol, E.K., Yalçın, F.N., Koca, U., Keleş, H., Yeşilada, E., 2010. Wound Healing Potential of Sambucus ebulus L. Leaves and Isolation of an Active Component, Quercetin 3-O-Glucoside, Journal of Ethnopharmacology, 129(1), 106-114.

15. Ebrahimzadeh, M.A., Nabavi, S.F., Nabavi, S.M., 2009. Antioxidant Activities of Methonal Extract of Sambucus ebulus L. Flower, Pakistan Journal of Biological Sciences: PJBS, 12(5), 447-450.

16. Ebrahimzadeh, M.A., Mahmoudi, M., Karami, M., Saeedi, S., Ahmadi, A.H., Salimi, E., 2007. Separation of Active and Toxic Portions in Sambucus ebulus, Pakistan Journal of Biological Sciences: PJBS, 10(22), 4171-4173.

17. Balkan, A., Ilter Akülke, A.Z., Bağatur, Y., Telci, D., Gören, A.C., Kırmızıbekmez, H., Yeşilada, E., 2017. Sambulin A and B, Non-Glycosidic Iridoids from Sambucus Ebulus, Exert Significant in Vitro Antiinflammatory Activity in LPS-Induced Raw 264.7 Macrophages Via Inhibition of Mapks's Phosphorylation, Journal of Ethnopharmacology, 206, 347-352.

18. Eser, F., Tutak, M., Onal, A., Meral, B., 2016. Dyeing of Wool and Cotton Fabrics with Leaves of Apple (Malus Domestica) Tree, 13(3), 289-298.

19. Özdemir, H., 2017. Dyeing Properties of Natural Dyes Extracted from the Junipers Leaves (J. excelsa Bieb. and J.oxycedrus L.), Journal of Natural Fibres, 14(1), 134-142. 
